\title{
Applying the Life Cycle Assessment (LCA) to Estimate the Environmental Impact of Selected Phases of a Production Process of Forming Bottles for Beverages
}

\author{
Patrycja Bałdowska-Witos, Robert Kasner, and Andrzej Tomporowski
}

\begin{abstract}
The study concerns the current issues of the impact of packaging on the natural environment. The main goal was to analyse the life cycle (LC) of a beverage bottle made of polyethylene terephthalate. The functional unit comprised a total of 1000 PET bottles with a capacity of 11 . The limit of the adopted system included steps from the moment of delivery of preforms to the production plant until they were properly shaped in the process of forming beverage bottles. Excluded from the system were the further stages of the production process, such as beverage bottling, labelling or storage/distribution. The processes related to the transport and storage of the raw material were also excluded. The LCA analysis was performed using the program of the Dutch company Pre Consultants called SimaPro 8.4.0. The "ReCiPe 2016" method was selected for the interpretation of lists of emitted chemicals. The results of the tests were presented graphically on bar charts and verified and interpreted.
\end{abstract}

\section{Introduction}

Activities of environmental organizations aimed at the development of proecological behaviour of the population effectively communicate about positive and negative environmental impacts [1]. The model of behaviour shaped over the years has led to the development of various methods for identifying the occurrence of environmental threats [2]. An example of a method successfully implemented in industrial practice is the more and more frequently used life cycle assessment (LCA) $[3,4]$. The LCA technique represents a new approach to assessing the potential environmental impacts of the beverage bottle manufacturing process. The growing ecological awareness of the society obliges production plants to carry out

\footnotetext{
P. Bałdowska-Witos $(\bowtie) \cdot R$. Kasner $\cdot$ A. Tomporowski

Department of Technical Systems Engineering, Faculty of Mechanical Engineering,

University of Science and Technology in Bydgoszcz, Bydgoszcz, Poland

e-mail: patrycja.baldowska-witos@utp.edu.pl
} 
environmental analysis. Such behaviour forces enterprises to strive for continuous improvement of the production process [4]. Change or modernization of technology should limit or minimize negative environmental impacts, take care of the environment and reduce or eliminate the negative effects of the production process [5]. The paper presents the results of the assessment of environmental impacts used in the technological process of bottle production. The goal of the study was to determine the potential levels of impact of individual technological operations on the condition of the natural environment and human health throughout the entire cycle of shaping bottles for beverages.

\section{Materials and Methods}

\subsection{Research Methodology}

The assessment of environmental loads was carried out for the production process of shaping bottles for beverages adopted in the study [6]. Collected industrial data from the bottle blow moulding machine made it possible to transform these data into the adopted functional unit. The analysis was performed using the ReCiPe 2016 method. Potential magnitudes of impacts from all environmental impacts were analysed $[3,6]$.

\subsection{Determination of Goal and Scope}

LCA is a tool used to assess the overall environmental impact of a product from "cradle to grave" [6]. For this purpose, the technological process of shaping PET bottles in Poland was assessed. The process is broken down into six unit operations, taking into account the demand for media and materials [6, 7]. The scope of the analysis included preform conveyor (CP), heating preforms (HP), stretching and lengthening the preform (SLP), blowing preforms (BP), degassing the bottle (DB) and cooling the finished bottle (CB).

\subsection{System Boundary and Functional Unit}

Six technological operations were adopted for the analysis (Fig. 1). As a result, the technological operations of the adopted processes were burdened with the same simplifications, which allowed assuming the exclusion level below $0.01 \%$ of the share in the entire life cycle. In inventory analysis, the examined systems and their system boundaries are defined, and process flow diagrams are drawn. Data collected 


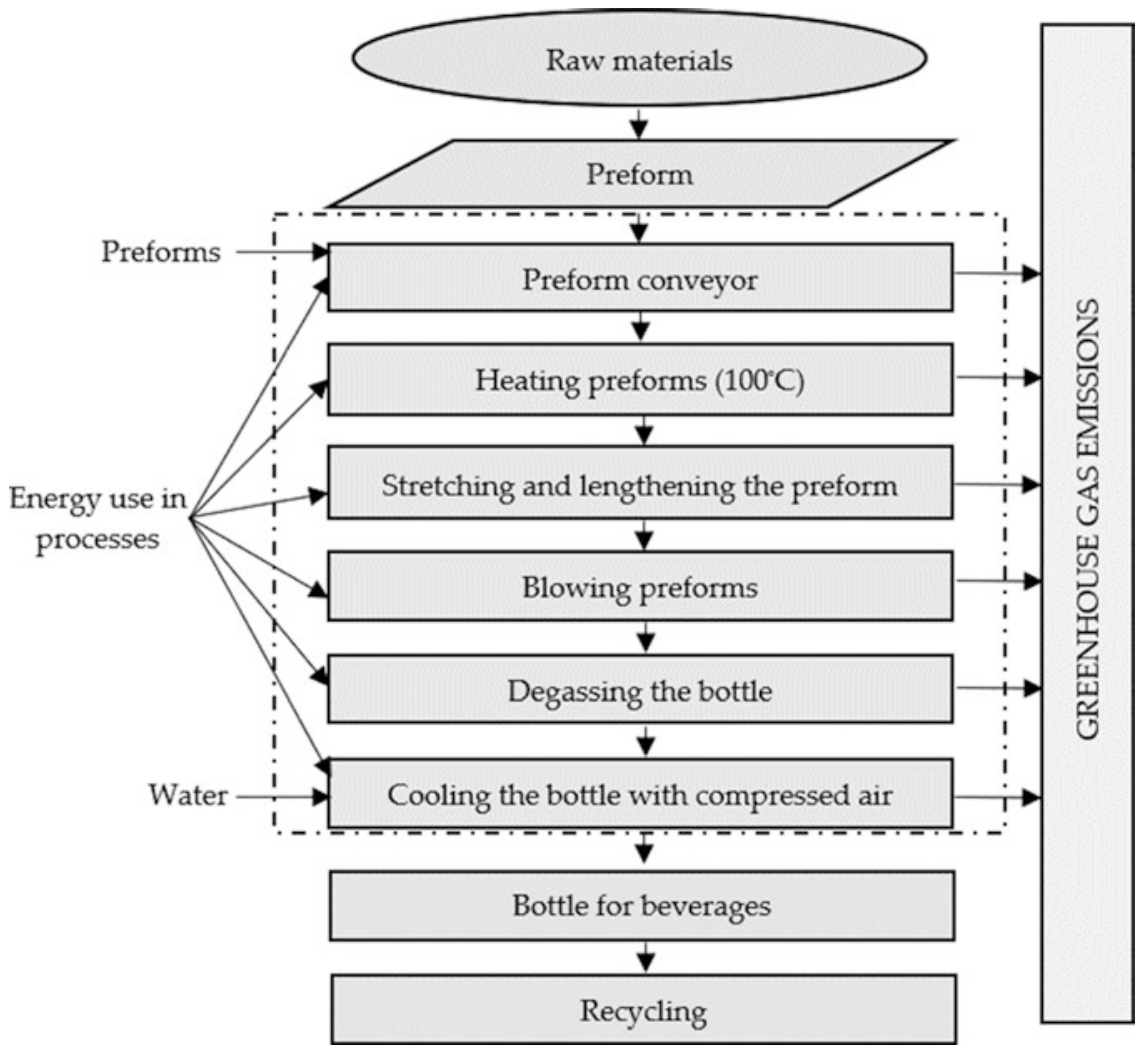

Fig. 1 Block diagram of the PET bottle production process

includes production, resource consumption and energy consumption. The functional unit adopted for the research was determined on the basis of data collected from the production company. It describes the production of 1000 bottles with a capacity of 11 .

\section{Results}

The first stage of the research included defining the objectives and scope of the analysis, including checking the completeness and compliance of the adopted measurement data. The second stage of the research included the results of the analysis of the set of inputs and outputs. Developed on the basis of analytical results, it can be concluded that greenhouse gases responsible for the greenhouse effect, ultimately causing global warming, such as carbon dioxide and methane, are often released to the atmosphere from natural causes and anthropogenic origin $[4,8]$. 
Potentially, the greatest negative impact on climate change was recorded for the degassing process of the finished product (DALY 1.16347E-08) (Fig. 2). Lower emission levels were observed for terrestrial ecosystems (3.51106E-11 species.yr) (Fig. 3) and freshwater ecosystems (9.5902E-16 species.yr) (Fig. 4). All of the three impact categories presented show the share of the raw material in the entire process of shaping the PET bottle at the level of approx. 78\% of the impact in a given impact category. In the case of the stratospheric ozone depletion category, the highest potential environmental damage was caused by the degassing of the finished bottle (Fig. 5).

The emissions of non-carcinogenic toxicity for human were highest during the degassing step of the shaped PET bottle (8.04032E-11 DALY), while the second value in terms of emission was the bottle pressure forming process and the process of automatic stretching and lengthening of the previously heated preform (Fig. 7).

Fig. 2 Global warming, human health

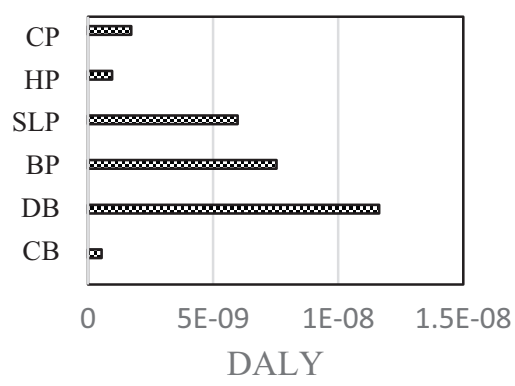

Fig. 3 Global warming, terrestrial ecosystems

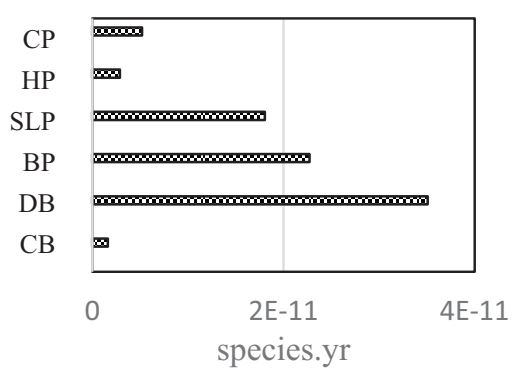

Fig. 4 Global warming, freshwater ecosystems

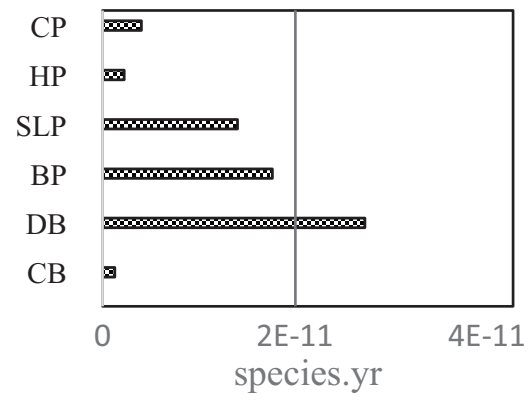


Fig. 5 Stratospheric ozone depletion

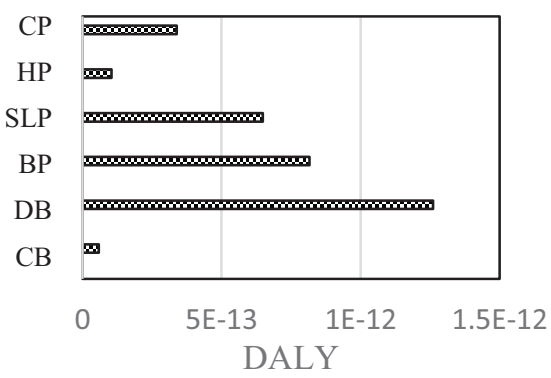

Fig. 6 Human carcinogenic toxicity

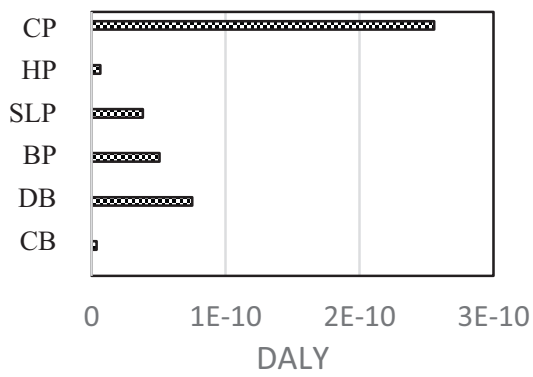

Fig. 7 Human noncarcinogenic toxicity

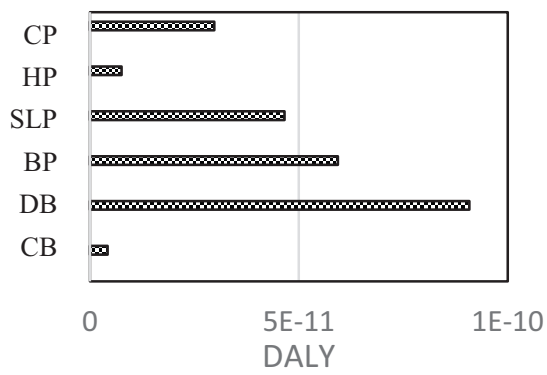

The total share of PET material in the technological process of shaping a PET bottle was only 1.76E-09 DALY. Significantly lower emission levels were observed for the whole human carcinogenic toxicity category (Fig. 6). The source of electricity is largely responsible for the amount of non-carcinogenic compounds emitted, and the amount of their emissions increases in stages as the production process progresses.

The ozone layer lies in the Earth's atmosphere and plays a key role in protecting living forms of nature [4]. Based on the analysis, it is proved that the process of shaping bottles exhibits greater environmental damage in the case of category zone formation, human health (Fig. 8) than in the case of category ozone formation, terrestrial ecosystems (Fig. 9).

Ecotoxicity of the aquatic and terrestrial environment results from the release of poisonous and toxic substances into the environment. Freshwater ecotoxicity shows the highest potential emission value specified for the degassing process of PET bottles (1.74682E-11 species.yr) (Fig. 11). The greatest potential impact on terrestrial ecotoxicity was exerted by degassing the PET bottle and was 1.79512E-11 
Fig. 8 Ozone formation, human health

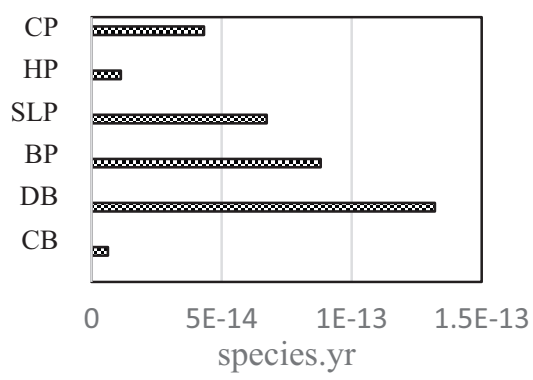

Fig. 9 Ozone formation, terrestrial ecosystems

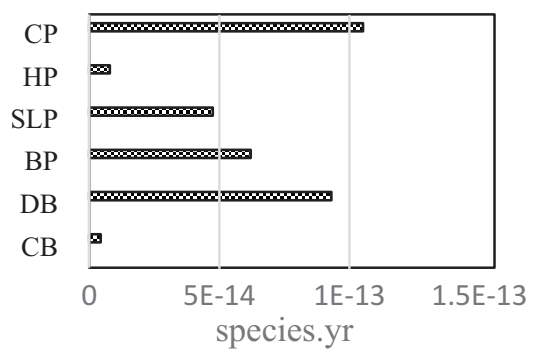

Fig. 10 Terrestrial ecotoxicity

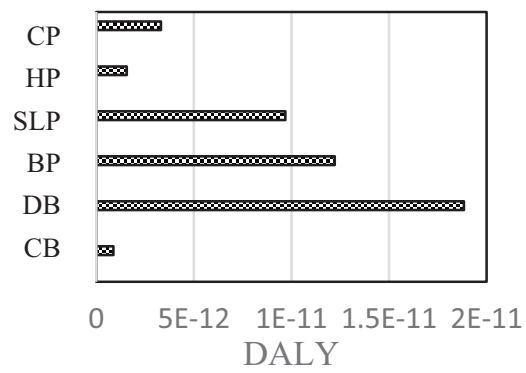

species.yr. (Fig. 10). Among the six analysed unit processes, the lowest negative impact was noted for the cooling process of the shaped bottle.

Acidification of the terrestrial environment is caused by a lowering of the $\mathrm{pH}$ value. This phenomenon occurs as a result of disturbance of the ecological balance of the processes of energy and matter exchange between elements of ecosystems [4]. The process of cooling the finished product had the lowest negative impact in the entire shaping process, while the degassing process of the bottle had the greatest negative impact. Lower emission levels were observed for the terrestrial acidification category (Fig. 12). Characterizing the entire process of creating the bottle, the degassing process of the finished product (5.72E-12 species.yr) had the greatest impact on the land use category and slightly less (3.68E-12 species.yr) on the preform pressure shaping process, and nearly $1 \%$ of the impact was recorded for the preform-in-mould stretching and elongation process, and less than $1 \%$ for the preform processes prior to heating, heating and cooling the finished product (Fig. 13).

Ionizing radiation is a phenomenon that has always been present in the surrounding environment [4]. The greatest potential negative impact was emitted by one of 
Fig. 11 Freshwater ecotoxicity

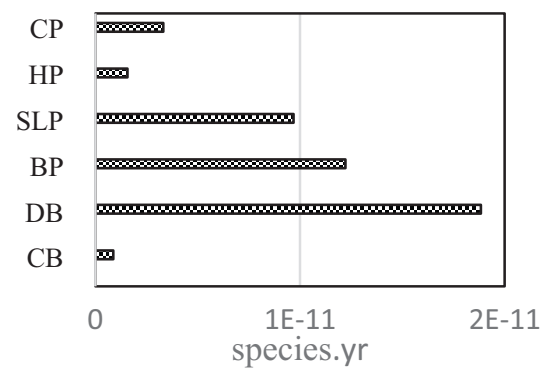

Fig. 12 Terrestrial acidification

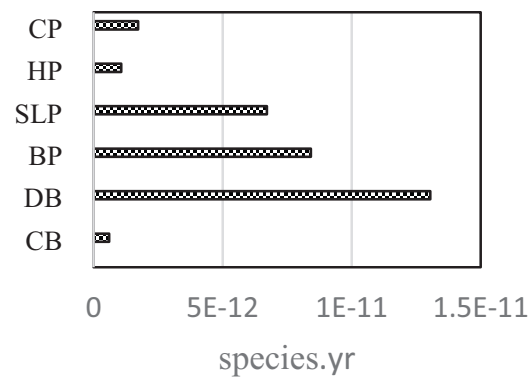

Fig. 13 Land use

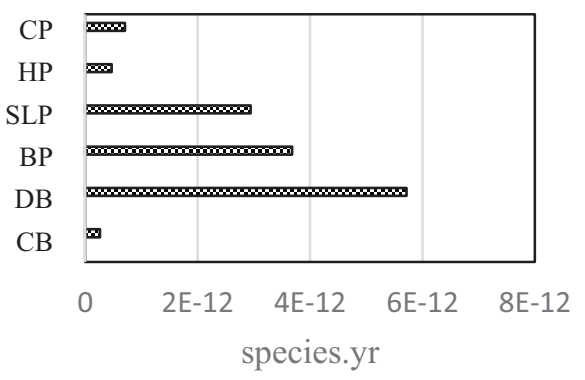

the sub-processes related to the amount of finished/semi-finished product used in the process - PET preform. The value of the issue was 2.11051E-13 DALY (Fig. 14). Local values of air pollutants generated by production plants do not provide accurate information on the scale of local emissions. As a result of the conducted analysis, it was determined that the greatest negative impact of the bottle shaping process on human health was recorded for the process of creating a PET bottle (1.18812E-08 DALY) at the stage of degassing the finished product. The lowest value of negative particle emissions affecting human health was determined for the PET bottle cooling process (4.59705E-10 DALY) (Fig. 15).

The PET bottle shaping process showed the higher potential level of adverse effects in the preform collection process for the reheating oven for the mineral resource scarcity category (Fig. 16) than for the fossil resource scarcity (Fig. 17). With the growing global demand for mineral resources, it is important to analyse whether the resources of geologically and technically available minerals in the Earth's crust can meet the future needs of humanity. Increasing recycling, material 
Fig. 14 Ionizing radiation

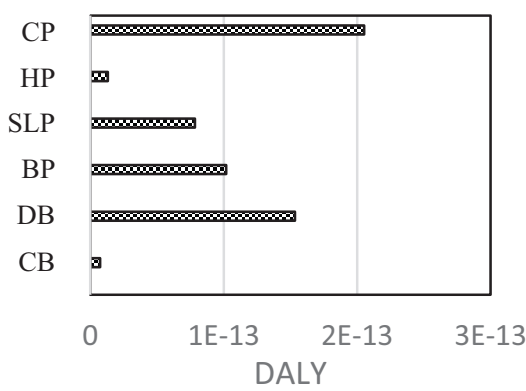

Fig. 15 Fine particulate matter formation

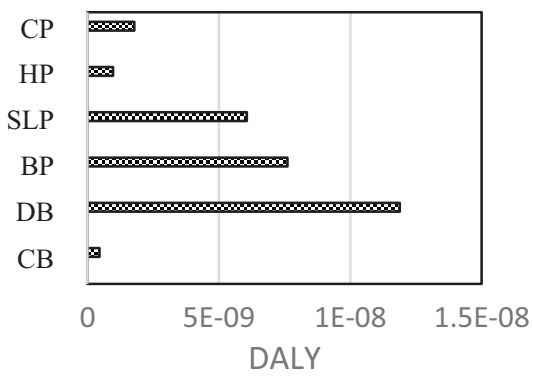

Fig. 16 Mineral resource scarcity

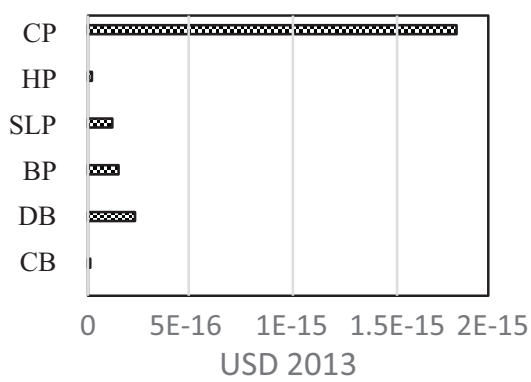

Fig. 17 Fossil resource scarcity

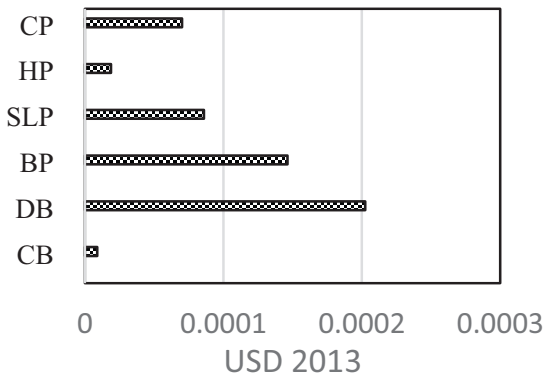


efficiency and demand management will surely play an important role in meeting future generations. A significant high value of potential impacts was recorded for the fossil resource scarcity category. The bottle with the greatest impact on this category was the PET bottle (8.58689E-05 USD2013) in the preform stretching and elongation process; the process of taking the preforms to the heating furnace (7.00854E-05 USD2013) was responsible for a slightly smaller amount of negative effects. This phenomenon is related to the fact that PET requires continuous extraction of fossil fuels, resulting in their depletion. This proceeding confirmed the highest staged impact of bottle production, and therefore the PET bottle probably had the greatest impact in the mineral extraction category. The production of the bottle had a slightly smaller impact in this category, possibly due to the fact that resource extraction is also needed.

Water consumption has an impact on human health and the quality of aquatic and terrestrial ecosystems. Water is critical to industry, the planet and people around the world. The production plant is a tycoon in the production of beverage bottles in the world. It uses a significant amount of the raw material, which is polyethylene terephthalate. However, its production significantly affects the condition of the natural environment. It was shown that for each of the two analysed impact categories, it was

Fig. 18 Water consumption, human health

Fig. 19 Water consumption, aquatic ecosystems
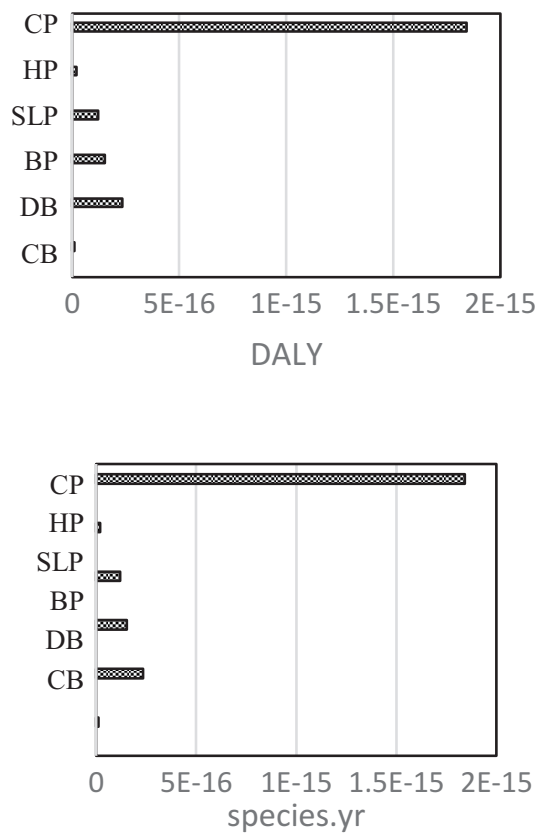
the preform conveyor operation that showed the highest potential negative environmental damage (Figs. 18 and 19).

\section{Conclusion}

The presented analyses of the technological processes of shaping bottles for beverages are characterized by various potential impacts on the condition of the natural environment. The environmental life cycle assessment [9] allowed for the conclusion that at the operational stage, the greenhouse gas emission index depends on the amount of electricity used in the production process [10]. The high level of impact on human health is determined by the raw material used in the production process polyethylene terephthalate. In order to reduce the emission of negative impacts on the natural environment, producers of the food sector should constantly look for substitutes for raw materials from exhaustible fossil resources. The right direction of development is the popularization of biodegradable raw materials of natural origin. There is an urgent need for further research related to the environmental assessment of the beverage bottle manufacturing processes. In further considerations, the development of a method of waste management in the production process should be considered.

\section{References}

1. Mannheim, V., Fehér, Z. S., \& Siménfalvi, Z. (2019). Innovative solutions for the building industry to improve sustainability performance with life cycle assessment modelling. In Solutions for sustainable development (pp. 245-253). CRC Press.

2. Piasecka, I., Bałdowska-Witos, P., Piotrowska, K., \& Tomporowski, A. (2020). Eco-Energetical life cycle assessment of materials and components of photovoltaic power plant. Energies, 13, 6.

3. Bałdowska-Witos, P., Kruszelnicka, W., Kasner, R., Tomporowski, A., Flizikowski, J., Kłos, Z., Piotrowska, K., \& Markowska, K. (2020). Application of LCA method for assessment of environmental impacts of a Polylactide (PLA) bottle shaping. Polymers, 12, 388. https://doi. org/10.3390/polym 12020388

4. Bałdowska-Witos, P., Kruszelnicka, W., Kasner, R., Rudnicki, J., Tomporowski, A., \& Flizikowski, J. (2019). Impact of the plastic bottle production on the natural environment. Part 1. Application of the ReCiPe 2016 assessment method to identify environmental problems. Przemysl Chemiczny, 98(10), 1662-1667.

5. Kłos, Z. (2002). Ecobalancial assessment of chosen packaging processes in food industry. International Journal of Life Cycle Assessment, 7, 309.

6. Bałdowska-Witos, P., Kruszelnicka, W., Kasner, R., Tomporowski, A., Flizikowski, J., \& Mrozinski, A. (2019). Impact of the plastic bottle production on the natural environment. Part 2. Analysis of data uncertainty in the assessment of the life cycle of plastic beverage bottles using the Monte Carlo technique. Przemysl Chemiczny, 98, 1668-1672.

7. Kruszelnicka, W., Marczuk, A., Kasner, R., Bałdowska-Witos, P., Piotrowska, K., Flizikowski, J., \& Tomporowski, A. (2020). Mechanical and processing properties of Rice grains. Sustainability, 12, 552. https://doi.org/10.3390/su12020552 
8. Bałdowska-Witos, P., Kruszelnicka, W., Kasner, R., Tomporowski, A., Flizikowski, J., Kłos, Z., Piotrowska, K., \& Markowska, K. (2020). Application of LCA method for assessment of environmental impacts of a Polylactide (PLA) bottle shaping. Polymers, 12, 388. https://doi. org/10.3390/polym 12020388

9. Piasecka, I., Bałdowska-Witos, P., Piotrowska, K., \& Tomporowski, A. (2020). Eco-Energetical life cycle assessment of materials and components of photovoltaic power plant. Energies, 13, 1385. https://doi.org/10.3390/en13061385

10. Joachimiak-Lechman, K., Selech, J., \& Kasprzak, J. (2018). Eco-efficiency analysis of an innovative packaging production: Case study. Clean Technologies and Environmental Policy, 21(2), 339-350. https://doi.org/10.1007/s10098-018-1639-7

Open Access This chapter is licensed under the terms of the Creative Commons Attribution 4.0 International License (http://creativecommons.org/licenses/by/4.0/), which permits use, sharing, adaptation, distribution and reproduction in any medium or format, as long as you give appropriate credit to the original author(s) and the source, provide a link to the Creative Commons license and indicate if changes were made.

The images or other third party material in this chapter are included in the chapter's Creative Commons license, unless indicated otherwise in a credit line to the material. If material is not included in the chapter's Creative Commons license and your intended use is not permitted by statutory regulation or exceeds the permitted use, you will need to obtain permission directly from the copyright holder. 